\title{
Micrometer size grains of hot isostatically pressed alumina and its characterization
}

\author{
A K MALLIK*, S GANGADHARAN, S DUTTA and D BASU \\ Central Glass \& Ceramic Research Institute, Kolkata 700 032, India
}

MS received 9 February 2009; revised 2 July 2009

\begin{abstract}
Alumina samples were prepared from two different particle size powders. Finer particle compacts when heated along with coarser particle compacts at same processing temperatures produce bigger grain microstructures due to higher grain growth. An unconventional method of etching by molten $\mathrm{V}_{2} \mathrm{O}_{5}$ was adopted to look at the microstructure for accuracy in reported data. On an average starting with finer particles give microstructure with a grain size of $5.5 \mu \mathrm{m}$ and starting with coarser particles, give microstructure with $2 \cdot 2 \mu \mathrm{m}$ average grain size. The flexural strength is around $400 \mathrm{MPa}$ for alumina samples prepared from finer powder in comparison with about 550 MPa for alumina samples prepared from coarser powder. The Vickers hardness in $5.5 \mu \mathrm{m}$ grain microstructure is around $20 \mathrm{GPa}$ in comparison to about $18 \mathrm{GPa}$ in microstructure with smaller grains of $2 \cdot 2 \mu \mathrm{m}$ size.
\end{abstract}

Keywords. Alumina; microstructure; hot isostatic pressing.

\section{Introduction}

Alumina is the most studied system in the field of ceramics. There are many applications of this material in the field of refractories, abrasives, electro-ceramics, bio-ceramic implants and many more. There is a chance of failure of this material due to its inherent brittleness which leads to catastrophic failure. The improvement of this material lies in betterment of material properties as well as in better design. Over the decades, ceramists have enhanced the technology of alumina ceramics (Munro 1997; Rahaman et al 2007) by purer material selection and better processing technologies. It is in vogue to hot isostatically press alumina ceramics for making denser body. There are extensive literatures on densification of alumina ceramics by hot-isostatic-pressing (HIPing) with or without presintering (Kang and Yoon 1987; Uematsu et al 1989, 1990; Mizura et al 1992). Dong-Woo (Shin et al 1990) reported microstructure mechanical property correlation in hot-isostatically-pressed (HIPed) alumina. They have reported presence of surface compressive stress due to transformation toughening of ZTA samples during hipping. McCoy (Wills and McCoy 1985) in their paper have reported interface-reaction-controlled kinetics of HIPing in sub micrometer alumina powder. Probable mechanism of densification is grain-boundary diffusion (Paladino and Coble 1963; Hammer and Brook 1980; Artz et al 1981). McCoy et al have demonstrated that densification rate is

\footnotetext{
*Author for correspondence (amallik@cgcri.res.in)
}

proportional to the square of the applied pressure and densification does not start below a threshold value, which is $13.8 \mathrm{MPa}$ for $1.2 \mu \mathrm{m}$ grain size alumina (Cannon et al 1980). Cannon et al (1980) also proposed a mechanism involving grain-boundary dislocation movement under applied pressure.

Properties, such as hardness, wear, electrical, optical etc of densely sintered alumina body depend on final microstructure after sintering and hot iso-static pressing. Therefore, it is essential to know the exact microstructure of the sintered body for better prediction of final properties. As far as our knowledge is concerned, there is no literature available on actual post processing alumina microstructure, chemically or otherwise etched and thereby its properties. All the literature correlates badly etched or thermally etched microstructural features and corresponding properties. Densely sintered alumina body is difficult to etch because of its chemical inertness to most of the chemicals and other methods such as thermal etching (Chen and Tuan 2000) leads to grain growth and therefore, cannot represent actual post processing alumina microstructural features. SEM micrographs of fractured surfaces neither provide microstructure of densely-sintered body nor shows exact grain size (for intra-granular fracture). Here we have adopted a method of chemical etching by molten $\mathrm{V}_{2} \mathrm{O}_{5}$ which etches (Katz and Hurley 1990) the hot iso-statically pressed alumina without altering actual microstructural features. (Authors have also tried etching with boiling phosphoric acid which did not etch the polished alumina samples). The grain size values calculated from molten $\mathrm{V}_{2} \mathrm{O}_{5}$ etched micrographs are correct 
values as etching process is not associated with grain growth phenomenon during thermal etching. Here we can claim that for the first time properties of alumina have been measured alongwith actual microstructural features after processing.

Rice (1997) reviewed strength of alumina and its properties are well documented by Munro (1997) and Rahaman et al (2007). Grain size has pronounced effect on hardness and other mechanical properties as depicted by different workers (Armstrong 1987, 2001; Petch and Armstrong 1989; Rice et al 1994; Krell 1995; Xu and Jahanmir 1995; Franco et al 1997; Muchtar and Lim 1998). The typical values for hot isostatically pressed alumina ceramic with $1.8 \mu \mathrm{m}$ grain size are as follows: Vicker's hardness, $2000 \mathrm{HV}$ (19.61 GPa); Young's modulus, $380 \mathrm{GPa}$; flexural strength, $580 \mathrm{MPa}$ with sp. gr. of 3.98 (source, Rahaman et al 2007).

In the present study we have synthesized hot isostatically pressed alumina ceramic samples using two different precursor powders. After processing we prepared the sample for characterization. We have etched the samples using molten $\mathrm{V}_{2} \mathrm{O}_{5}$, thereby did not alter the actual microstructural features developed due to processing. Samples were characterized for density, crystallinity and grain size and its hardness, flexural strength and Young's modulus properties were evaluated.

\section{Experimental}

We have used two commercially available $\alpha$-alumina powders viz. A 16-SG, Almatis ACC Ltd. India, 99.99\% purity, particle size distribution, $0.3-0.7 \mu \mathrm{m}$; and TM DAR, Taimei Chemical Co. Japan, $99.99 \%$ purity, mean particle size, $170 \mathrm{~nm}$. The powders were cold iso-statically pressed (EPSI N.V., SO 10036, Belgium) at $150 \mathrm{MPa}$ pressure into cylindrical bodies and then presintered at $800^{\circ} \mathrm{C}$ to provide sufficient strength for green machining of the compacts. Rectangular blocks of $45 \times 4.5 \times 3.5 \mathrm{~mm}^{3}$ dimension were cut out of presintered cylindrical body by turning and turned bodies were then sintered at three different temperatures $\left(1550^{\circ}, 1540^{\circ}, 1520^{\circ} \mathrm{C}\right)$ for $2 \mathrm{~h}$ (table 1 ). The sintered bodies were hot-isostatically-pressed (HIPed) at two different temperatures viz. $1550^{\circ} \mathrm{C}$ and $1475^{\circ} \mathrm{C}$, and at a fixed $200 \mathrm{MPa}$ pressure for $30 \mathrm{~min}$ (Avure QIH6 , USA). The density was measured simply by using Archimedes principle. These blocks were then ground in a surface grinding machine with the use of 400 grit and 600 grit diamond wheels and opposite faces of the blocks were made flat and parallel with each other. The flat parallel samples were then hand-lapped with lapping compound and then sequentially polished on a polishing wheel using $8 \mu \mathrm{m}, 3 \mu \mathrm{m}, 1 \mu \mathrm{m}$ and at last with $0.25 \mu \mathrm{m}$ diamond pastes. The surface roughness of the final samples was measured by surface profilometer (Surtronic $3 p$, Form Talysurf Plus, Rank Taylor Hobson Ltd. UK). Less than $0.05 \mu \mathrm{m} R_{\mathrm{a}}$ value of final roughness was always achieved. 3-Pt Flexural strength was done using Instron made Universal testing Machine, model no. 5500 R 1185 UK. The strength values $(\sigma)$ of the samples were calculated from the following relationship:

$$
\sigma=3 w l / 2 b d^{2}
$$

where $w$ is the breaking load, $l$ the distance between the two support rollers, $b$ and $d$ are the width and thickness of the respective samples. Instron Wolpert, GmbH (model no. DIA TESTOR 7021) hardness tester was used to determine Vickers hardness from the following relationship:

$$
H_{\mathrm{v}}=2 P \sin 68^{\circ} / d^{2},
$$

where $P$ is the indentation load (200 gmf and $15 \mathrm{~s})$ and $d$ the size of the diagonals of the impression. Hardness values expressed in HV were converted into SI unit of GPa by a multiplication factor of 0.009807 . Elastic modulus was measured by ultrasonic pulse-echo technique the details of which have been published elsewhere (Basu et al 1996). The samples were etched by molten $\mathrm{V}_{2} \mathrm{O}_{5}$. The samples were tied with individual platinum wires and were immersed inside a platinum crucible filled with molten vanadium pentoxide at $950^{\circ} \mathrm{C}$. The experiment was done with a raising hearth furnace. $\mathrm{V}_{2} \mathrm{O}_{5}$ powder was kept inside a platinum crucible. Once the desired temperature was achieved, hearth was lowered down and samples were kept inside the crucible. Soon after, the hearth was raised up and alumina samples were kept inside for $45 \mathrm{~s}$. Time was measured with a stopwatch. $45 \mathrm{~s}$ was sufficient for etching the samples. Solidified $\mathrm{V}_{2} \mathrm{O}_{5}$ sticking with the samples were removed with concentrated hydrochloric acid and thereafter, rinsing with water. Etched samples were seen under scanning electron microscope (LEO 430i STEROSCAN, UK) for grain size measurement by line intercept method. ASTM Standard E 112-88 describes the lineal intercept method, in general, and the Heyn procedure, in particular. The X-ray diffraction patterns of the samples were recorded in X'pert Pro MPD diffractometer (PANanalytical) operating at $45 \mathrm{kV}$ and $35 \mathrm{~mA}$ using Ni-filtered $\mathrm{CuK} \alpha$ radiation. The XRD data were recorded in $X^{\prime}$ celerator with a step size, $0.02^{\circ}(2 \theta)$, step time, $25 \mathrm{~s}$, from $10^{\circ}-100^{\circ}$

\section{Results and discussion}

We selected two commercially available $\mathrm{Al}_{2} \mathrm{O}_{3}$ precursor powders of two different sizes viz. coarser precursor of $0 \cdot 3-0.7 \mu \mathrm{m}$ size and finer precursor of $0.17 \mu \mathrm{m}$ average size. Three sintering temperatures have been chosen: $1520^{\circ} \mathrm{C}, 1540^{\circ} \mathrm{C}$ and $1550^{\circ} \mathrm{C}$. The hot iso-static pressing temperatures were $1475^{\circ} \mathrm{C}$ and $1550^{\circ} \mathrm{C}$ (refer to table 1 ). For a given starting powder size of $0.3-0.7 \mu \mathrm{m}$, there is usual grain growth phenomenon with increase in sintering 
Table 1. Processing temperature-property correlation.

\begin{tabular}{|c|c|c|c|c|}
\hline $\begin{array}{l}\text { Precursor particle } \\
\text { size }(\mu \mathrm{m})\end{array}$ & $\begin{array}{c}\text { Sintering } \\
\text { temperature }\left({ }^{\circ} \mathrm{C}\right)\end{array}$ & $\begin{array}{c}\text { HIP } \\
\text { temperature }\left({ }^{\circ} \mathrm{C}\right)\end{array}$ & $\begin{array}{l}\text { Average grain size } \\
\qquad(\mu \mathrm{m})\end{array}$ & $\begin{array}{l}\text { HIPed density } \\
\text { (g/cc) }\end{array}$ \\
\hline Coarser $(0 \cdot 3-0 \cdot 7)$ & $\begin{array}{l}1520 \\
1540 \\
1550 \\
1520 \\
1540 \\
1550\end{array}$ & 1475 & $\begin{array}{c}1.42 \\
1.65 \text { (figure 1) } \\
2.95 \\
1.93 \\
2.36 \\
3.19\end{array}$ & $\begin{array}{l}3.94 \\
3.96 \\
3 \cdot 97 \\
3.95 \\
3 \cdot 96 \\
3.98\end{array}$ \\
\hline Finer $(0.17$ avg. $)$ & $\begin{array}{l}1520 \\
1540 \\
1520 \\
1540\end{array}$ & $\begin{array}{l}1475 \\
1550\end{array}$ & $\begin{array}{c}4 \cdot 78 \\
5 \cdot 27 \text { (figure 2) } \\
5.88 \\
6.39\end{array}$ & $\begin{array}{l}3.97 \\
3.97 \\
3.96 \\
3.98\end{array}$ \\
\hline
\end{tabular}

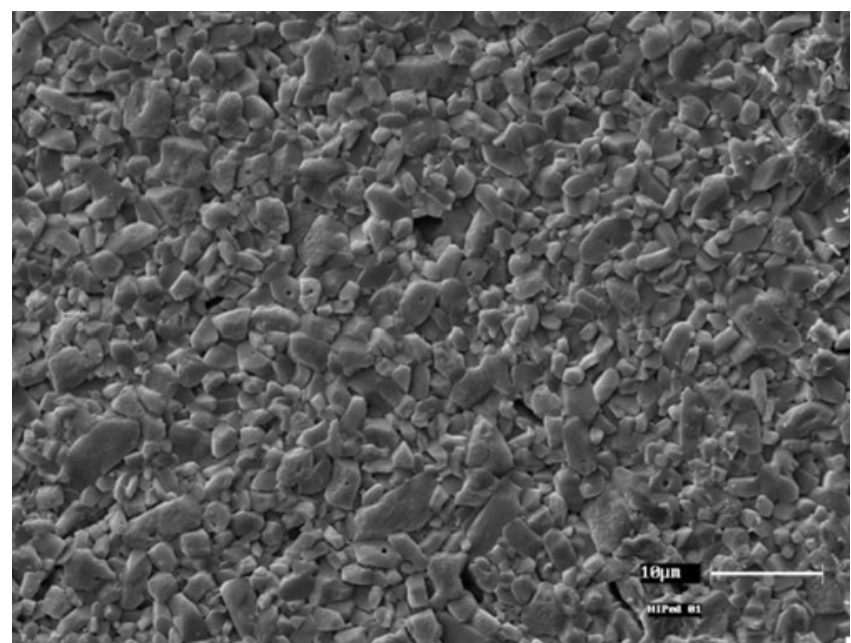

Figure 1. SEM micrographs of smaller grain microstructure alumina samples prepared from coarser precursor as described in table 1 .

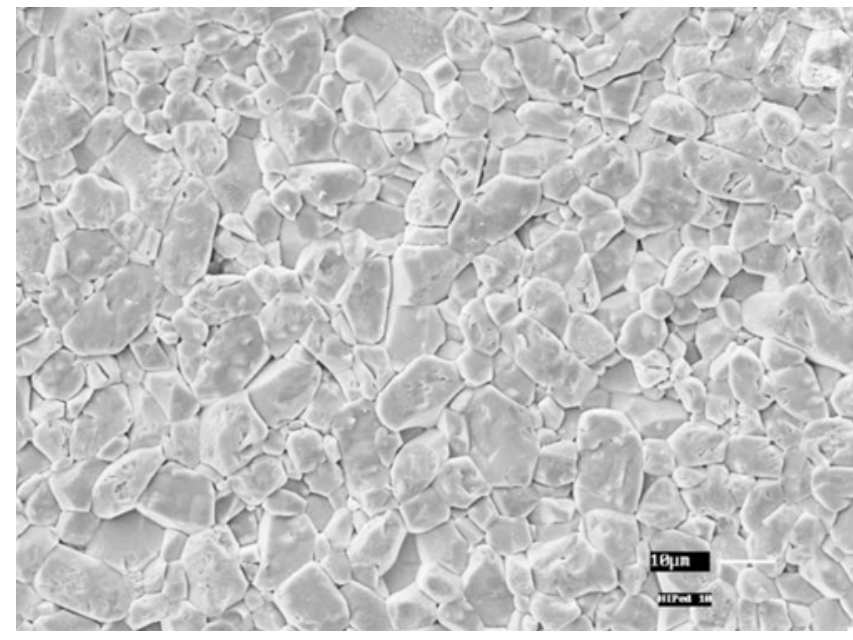

Figure 2. SEM micrographs of bigger grain microstructure alumina samples prepared from finer precursor as described in table 1 .

temperature and hipping temperature. When the hot isostatic pressing temperature is $1475^{\circ} \mathrm{C}$, average grain size increases from $1.42 \mu \mathrm{m}$ to $2.95 \mu \mathrm{m}$ (although very negligible but measurable) with increase in sintering temperature from $1520-1550^{\circ} \mathrm{C}$ (grain size measurement was done by line intercept method). Similarly when hot isostatic pressing temperature is $1550^{\circ} \mathrm{C}$ there is as usual increase in average grain size from $1.93 \mu \mathrm{m}$ to $3.19 \mu \mathrm{m}$ (more pronounced effect compared to hipping at $1475^{\circ} \mathrm{C}$ ) with increase in sintering temperature from 1520 $1550^{\circ} \mathrm{C}$. Moreover, if we now compare the samples with same sintering temperature (say $1520^{\circ} \mathrm{C}$ ) but different hot isostatic pressing temperatures $\left(1475^{\circ} \mathrm{C}\right.$ and $\left.1550^{\circ} \mathrm{C}\right)$ we find higher hot isostatic pressing temperature cause higher grain growth $(1.42 \mu \mathrm{m} \mathrm{v} / \mathrm{s} 1.93 \mu \mathrm{m}$, respectively). To better understand we discuss another example of sample sintered at $1550^{\circ} \mathrm{C}$ when hipped at $1475^{\circ} \mathrm{C}$ gave a microstructure with $2.95 \mu \mathrm{m}$ average grain size, whereas the sample sintered at same $1550^{\circ} \mathrm{C}$ but hipped at $1550^{\circ} \mathrm{C}$ gave a microstructure with $3.19 \mu \mathrm{m}$ average grain sizes. The effect of sintering and hipping temperature on grain size is not so pronounced in this temperature range.

While using finer powder of $170 \mathrm{~nm}$ of average size as starting material and sintered and hipped at the same sequence, that is (a) sintered at $1520^{\circ} \mathrm{C}$ and $1540^{\circ} \mathrm{C}$ and then hipped at $1475^{\circ} \mathrm{C}$ and (b) sintered at $1520^{\circ} \mathrm{C}$ and $1540^{\circ} \mathrm{C}$ and then hipped at $1550^{\circ} \mathrm{C}$, we find the same trend in grain growth. The average grain size increases $(4.78 \mu \mathrm{m}$ to $6.39 \mu \mathrm{m})$ with sintering temperature as well as with hipping temperature.

Now to understand the effect of starting powder particle size on final microstructure, we compared the data with same processing conditions, that is same sintering and hipping temperature but with two starting powders. Samples sintered at $1520^{\circ} \mathrm{C}$ and hipped at $1475^{\circ} \mathrm{C}$ show average $1.42 \mu \mathrm{m}$ grain microstructure with coarser precursor particle and average $4.78 \mu \mathrm{m}$ grain microstructure for finer precursor particles. Similarly samples sintered at $1540^{\circ} \mathrm{C}$ and hipped at $1550^{\circ} \mathrm{C}$ show average $2.36 \mu \mathrm{m}$ grain microstructure with coarser precursor particle and average $6.39 \mu \mathrm{m}$ grain microstructure for finer precursor particles. There is enhanced grain growth with finer particle size, because higher surface energy of finer powder drives to higher growth kinetics under similar processing conditions. The results have been summarized 
Table 2. Effect of hot isostatic pressing on mechanical properties.

\begin{tabular}{lccccc}
\hline $\begin{array}{l}\text { Hipped } \\
\text { temp. }\left({ }^{\circ} \mathrm{C}\right)\end{array}$ & $\begin{array}{c}\text { Sintered } \\
\text { temp. }\left({ }^{\circ} \mathrm{C}\right)\end{array}$ & $\begin{array}{c}\text { Average grain } \\
\text { size }(\mu \mathrm{m})\end{array}$ & $\begin{array}{c}\text { Hardness } \\
(\mathrm{GPa})\end{array}$ & $\begin{array}{c}\text { 3-Pt. flexural } \\
\text { strength }(\mathrm{MPa})\end{array}$ & $\begin{array}{c}\text { Youngs' } \\
\text { modulus }(\mathrm{GPa})\end{array}$ \\
\hline 1475 & 1520 & $1 \cdot 42$ & $18 \cdot 45$ & 508 & 398 \\
& 1540 & $1 \cdot 65$ & $19 \cdot 19$ & 531 & 393 \\
1550 & 1550 & $2 \cdot 95$ & $19 \cdot 57$ & 578 & 398 \\
$\mathbf{1 4 7 5}$ & 1520 & $1 \cdot 93$ & 20.53 & 621 & 403 \\
& $\mathbf{1 5 2 0}$ & $\mathbf{4 . 7 8}$ & $\mathbf{1 9 . 9}$ & $\mathbf{3 8 1}$ & $\mathbf{4 0 5}$ \\
$\mathbf{1 5 5 0}$ & $\mathbf{1 5 4 0}$ & $\mathbf{5 . 2 7}$ & $\mathbf{2 1 . 3}$ & $\mathbf{4 6 7}$ & $\mathbf{4 0 1}$ \\
\hline
\end{tabular}

*Values in bold are of bigger grain microstructures

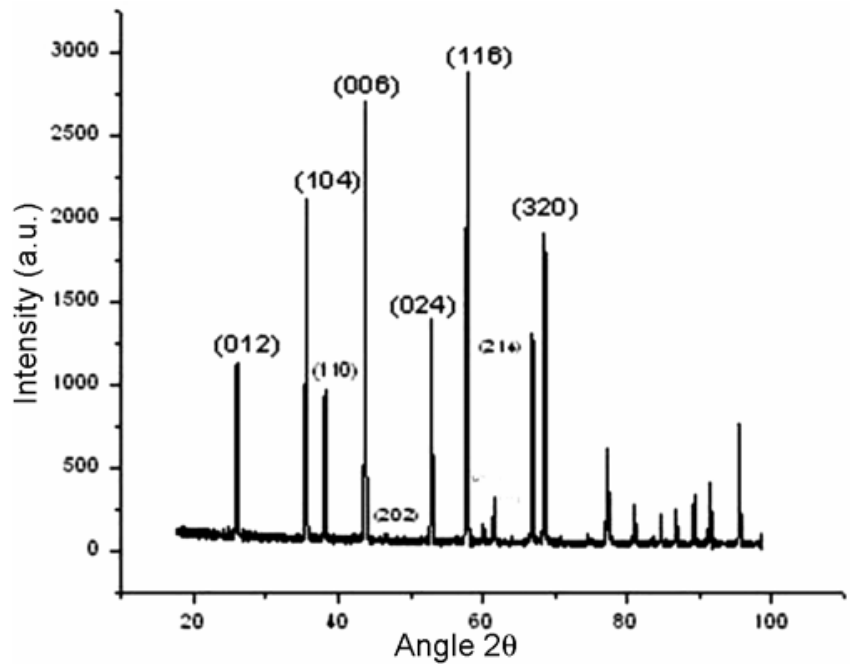

Figure 3. XRD peaks of bigger grain microstructure sample (figure 2).

in table 1 (figure 1 shows final microstructure of sample, prepared from coarser precursor and figure 2 shows final microstructure of sample, prepared from finer precursor, both the samples were sintered at $1540^{\circ} \mathrm{C}$ and hipped at $1475^{\circ} \mathrm{C}, 200 \mathrm{MPa}$ Ar gas pressure).

If we look at the density values after hipping, all of them have values $>3 \cdot 90$, which is ISO specification for medical grade alumina. The lowest being 3.94 sintered at $1520^{\circ} \mathrm{C}$ and hipped at $1475^{\circ} \mathrm{C}$. The best value of 3.98 was obtained by sintering at $1550^{\circ} \mathrm{C}$ and hipping at $1550^{\circ} \mathrm{C}$. It can be noted that theoretical density of alpha alumina is 3.99 (Igor and Brandon 1998). We have achieved 99.74\% of theoretical density for alumina.

Table 2 shows the Vickers hardness and three-point flexural strength values of the samples. The Young's modulus does not vary much with grain size among all the samples. It is always around $400 \mathrm{GPa}$. Samples hipped at $1475^{\circ} \mathrm{C}$ show improvement in flexural strength (each data point has been generated after averaging over atleast 5 samples) from 508, 531 to $578 \mathrm{MPa}$ with corresponding increase of sintering temperature from $1520^{\circ} \mathrm{C}$, $1540^{\circ} \mathrm{C}$ to $1550^{\circ} \mathrm{C}$ because of better crack healing. The trend is present also in samples prepared with finer pre- cursor particles (381 and $467 \mathrm{MPa}$ ). It is being observed that the flexural strength of samples prepared from finer particle size are lower (381 MPa) than samples prepared from coarser precursor particle $(508 \mathrm{MPa})$ processed together. This was contradicting intuition. But the reason is very obvious, the fracture strength of a ceramic depends on the size of critical crack length or $K_{\mathrm{Ic}}$. Since the size of grains becomes larger with finer precursor powder because of higher surface energy, the flaw sizes also become larger along with, and thereby the probability of finding crack of critical size is higher for finer precursor samples and hence their flexural strength is lower. The extent of crack healing during hot isostatic pressing is not enough to reduce the critical flaw density in the samples.

Vickers hardness for samples (average over atleast 5 identical samples and 5 readings per sample) prepared from coarser precursor (final microstructure with 1-3 $\mu \mathrm{m}$ grains) is in the range $18-20 \mathrm{GPa}$, whereas when started with finer precursor (with a 4-6 $\mu \mathrm{m}$ grain final microstructure) shows a negligible increase in hardness from 19-21 GPa. These values are in agreement with the literature values.

\section{Conclusions}

Hot isostatic pressing has helped in achieving $99.74 \%$ of theoretical density for $\alpha-\mathrm{Al}_{2} \mathrm{O}_{3}$. Suitable manipulation of precursor particle size can help in achieving very high hardness of 20-21 GPa and flexural strength of $550 \mathrm{MPa}$, while Young's modulus (400 GPa) does not vary among samples. The reported values are in agreement with the literature. For the first time exact microstructure of the sintered and hot isostatically pressed alumina has been revealed by novel chemical etching with molten $\mathrm{V}_{2} \mathrm{O}_{5}$ and precise grain size calculation reported with its mechanical properties.

\section{Acknowledgements}

Authors would like to thank Dr (Mrs) S Sen and Mrs $S$ Roy for their help in taking SEM micrographs. We would like to thank Dr S Majumdar for allowing us to do 
XRD measurements. Summer trainee student, Pranav Kumar, helped in grain size calculations by line intercept method. Mr J Chakraborty helped in alumina sample preparation. S K Dalui has helped in mechanical property measurements. The financial support was from the parent body, the Council of Scientific and Industrial Research, India (network project NMITLI, TLP 0002).

\section{References}

Armstrong R W 1987 Eng. Fract. Mech. 28529

Armstrong R W 2001 Int. J. Ref. Met. \& Hard Mater. 19251

Artz E, Ashby M F and Easterling K E 1981 Metall. Trans. A14 21

Basu D, Mukherjee S and Phani K K 1996 J. Mater. Sci. 31 1021

Cannon R M, Rhodes W H and Heuer A H 1980 J. Am. Ceram. Soc. 6346

Chen R Z and Tuan W H 2000 Thermal etching of alumina (The American Ceramic Society Bulletin) Vol. 79, pp 83-86

Igor Levin and Brandon David 1998 J. Am. Ceram. Soc. 811995

Franco A, Roberts S G and Warren P D 1997 Acta Mater. 451009

Hammer M P and Brook R J 1980 J. Mater. Sci. 153017

Kang Thae-Khapp and Yoon Duk N 1987 J. Am. Ceram. Soc. 70 C-49
Katz Joel D and Hurley George 1990 J. Am. Ceram. Soc. 73 2151

Krell A 1995 Mater. Sci. Engg. A209 156

Mizuta H, Oda K, Shibazaki Y, Machihide M and Ohshima K 1992 J. Am. Ceram. Soc. 75469

Muchtar A and Lim L C 1998 Acta Mater. 461683

Munro Ronald G 1997 J. Am. Ceram. Soc. 801919

Paladino A E and Coble RL 1963 J. Am. Ceram. Soc. 46 133

Petch N J and Armstrong R W 1989 Acta Metall. 372279

Rahaman Mohamed N, Yao Aihua, Sonny Bal B, Garino Jonathan P and Ries Michael D 2007 J. Am. Ceram. Soc. 90 1965

Rice R W, Wu C C M and Borchelt F 1994 J. Am. Ceram. Soc. 772539

Rice R W 1997 J. Mater. Sci. 321673

Shin Dong-Woo, Orr K K and Schubert Helmut $1990 \mathrm{~J}$. Am. Ceram. Soc. 731181

Uematsu Keizo, Kazuhisa Itakura, Masahiko Sekiguchi, Nozomo Uchida and Katsuichi Saito $1989 \mathrm{~J}$. Am. Ceram. Soc. 721239

Uematsu Keizo, Kazuhisa Itakura, Nozomo Uchida and Katsuichi Saito 1990 J. Am. Ceram. Soc. 7374

Wills Roger R and John Kevin McCoy 1985 J. Am. Ceram. Soc. $68 \mathrm{C}-95$

Xu H H K and Jahanmir S 1995 J. Mater. Sci. Lett. 14736 